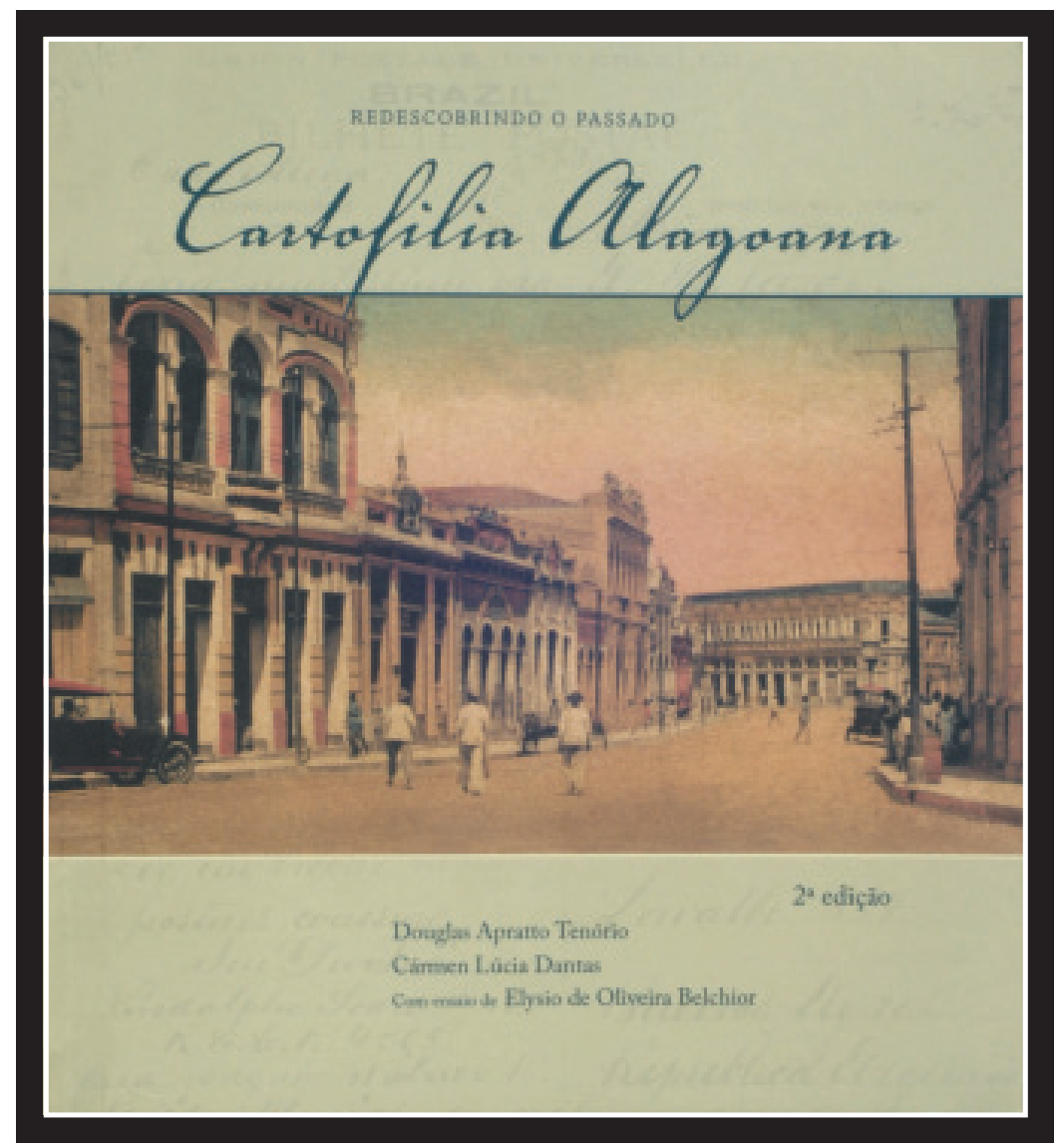

Redescobrindo o passado: cartofilia alagoana, de Douglas Apratto Tenório e Carmem Lúcia Dantas. 2.ed. Maceió: Sebrae, 2009, 120 p. Com ensaio de Elysio de Oliveira Belchior 


\title{
Estive em Alagoas e me lembrei de você
}

\author{
José de Arimathéia Cordeiro Custódio*
}

Na era do orkut e dos fotologs, o que será dos cartões postais? Terão eles o mesmo destino dos cartões natalinos, ou seja, ficarão cada vez mais raros? Não necessariamente. Vá a qualquer cidade turística brasileira e lá estão eles, pendurados nas bancas de revistas, nas lojas de artesanato, nos quiosques dos aeroportos.

Cartões postais não são apenas lembranças de viagens, para o viajante ou um amigo que infelizmente não estava lá. São documentos imagéticos, carregados de informação, significados e valor histórico. Como dizem os autores, "fotógrafos de apurado olhar lhes dedicaram um espaço especial, formulando séries temáticas que hoje enriquecem coleções e são disputadas como peças de rara importância". (TENÓRIO; DANTAS, 2009, p.12). Segundo a obra, a cartoteca da Biblioteca Fomey (Paris) possui mais de um milhão de postais.

Ao reunir mais de 110 cartões postais de paisagens alagoanas, a obra transporta o leitor a uma viagem ao final do século XIX e início do século XX. O objetivo, segundo Tenório e Dantas (2009, p.14), é "preencher o vazio na iconografia local, servindo para que Alagoas ingresse no interessante universo da cartofilia brasileira, abrindo um novo espaço para os pesquisadores". Carmem Dantas, uma das autoras, lembra, na página 55, que, no Nordeste, já Gilberto Freyre reconhecia o valor histórico dos postais na "elucidação de ambientes e de posturas do passado, de forma espontânea e atraente", em sua obra "Alhos e Bugalhos". Para o leitor, porém, o livro é um mergulho nos cenários urbanos e rurais de Maceió e de cidades do interior.

Os autores informam que o cartão postal surgiu na Europa na segunda metade do século XIX e rapidamente caiu no gosto popular, encontrando seu auge no período de 1880 a 1920, o que, no Brasil,

\footnotetext{
* Especialista em Fotografia e História Social. Doutor em Estudos da Linguagem pela Universidade Estadual de Londrina.
} 
corresponde à proclamação e consolidação da República, mescladas ao estilo da bélle epoque è chegada de novos modelos. Enfim, um tempo de transformações e transições, retratadas e gravadas para a posteridade graças aos postais.

No caso de Alagoas, a virada do século significou um movimento de urbanização, de perda sensível da força do poder senhorial rural (ainda que incipiente). É óbvio, porém, que certas marcas seriam inevitáveis por lá, afinal, Deodoro da Fonseca e Floriano Peixoto, os dois primeiros presidentes da República do Brasil, eram alagoanos. E Marechal Deodoro, a poucos quilômetros de Maceió, é hoje uma das cidades históricas mais importantes do estado.

O postal, diz Douglas Tenório, na página 51, foi uma novidade que chegou à capital alagoana "como um dos símbolos dos novos tempos que vão mudando os costumes antigos da época colonial e do Império, em meio a tantas outras novidades que são discutidas a aceitas pela elite urbana...".

A viagem a esta Alagoas histórica através dos cartões postais é cheia de surpresas e prazeres. Uma fotografia da praia de Ponta Verde (Maceió), em duas páginas, parece até pré-cabralina: totalmente selvagem. Ruas, casario, trapiches, igrejas, edifícios, praças - os locais são retratados e contam muito sobre os costumes e rotina diária dos moradores. As imagens não são isentas - elas valorizam certos elementos, como pessoas e fachadas de prédios. Tais sutilezas enriquecem a informação visual. São uma longa narrativa de um modo de vida que ficou mais de cem anos para trás.

O livro contém imagens de Penedo, Viçosa, São Miguel dos Campos, Rio Largo e Maceió. Talvez sejam as imagens desta última as que mais demonstram transformações: "Porque as ruas de Jaraguá, a Avenida da Paz, o Centro e o Bebedouro já não são mais os mesmos. Difícil é encontrar algum ponto que possa identificá-los como sendo o mesmo espaço". (TENÓRIO; DANTAS, 2009, p.72). Até Cecília Meirelles, citada na obra, passou por esta experiência, e se inspirou a escrever: "Onde estão água e festas anteriores? E a imagem da praça, agora, que será daqui a um ano, um mês, a um dia, a uma hora” (do poema 'Domingo na Praça'). 
Fotografias com um tempero "jornalístico" são igualmente encontradas no livro, como uma imagem da rua Joaquim Nabuco, em Penedo, alagada por uma cheia do rio São Francisco, em 1905/06.

Até linguistas podem se deliciar diante dos cartões postais da obra, pois vários trazem anotações, como aquelas que identificam o "pharol”, o "télégrapho" ou o "engenho de assucar", revelando interessantes variações diacrônicas. Na página 43, é o verso de um postal que aparece, expondo um texto de "5-2-916" (5 de fevereiro de 1916), enviado a Adhemar Travassos, morador da rua da Alegria, 7, em Recife. O texto informa que aquele é um dos cinco cartões "postaes" mandados ao referido destinatário.

Naquele tempo, em que as mensagens eram escritas com tinta e pena, não se podia errar. Uma gota de tinta no lugar errado poderia estragar tudo. Ainda assim, muitas vezes a alternativa era enviar o postal borrado mesmo. Curiosamente - aponta a obra - os cartões postais com tais borrões podem se tornar ainda mais atraentes aos olhos dos colecionadores. Para um cartofilista, há verdadeira fascinação em encontrar aquelas escritas que invadem todos os espaços do cartão, entre selos e carimbos. Percebese que até aí nem se cogitou falar do conteúdo das mensagens. Antes disso, já existe um tesouro histórico a ser explorado.

Está certo que a obra peca ao não trazer a devida legenda e identificação de cada imagem, no melhor formalismo acadêmico e documental. Mas, em compensação, traz extensa bibliografia, que vai de Roger Chartier a Boris Kossoy, passando por Ledo Ivo e Pedro Karp Vasquez. O ponto forte, é claro, é a coletânea de postais, "verdadeiros documentos da trajetória material de uma sociedade, dos seus monumentos e seu urbanismo", como lembram os autores, na página 20.

Douglas Tenório e Carmem Dantas, juntamente com Leda Maria de Almeida, já haviam publicado Arte sacra em Alagoas: um tesouro da memória (Brasília: Senado Federal, 2006), um verdadeiro convite a percorrer as ruas de cidades históricas alagoanas, como Penedo e Marechal Deodoro, e conferir de perto as muitas obras mostradas no livro. É claro que o convite foi aceito. 